\title{
Understanding educational change: Agency-structure dynamics in a novel design and making environment
}

\author{
Kristiina Kumpulainen \\ kristiina.kumpulainen@helsinki, .fi \\ University of Helsinki, Finland \\ Anu Kajamaa \\ anu.kajamaa@helsinki.fi \\ University of Helsinki, Finland \\ Antti Rajala \\ antti.rajala@helsinki.fi \\ University of Helsinki, Finland
}

\begin{abstract}
This study investigates agency-structure dynamics in students and teachers' social activity in a novel design and making environment in the context of the Finnish school system, which has recently undergone major curricular reform. Understanding that agency is an important mediator of educational change, we ask the following questions: How are agency-structure dynamics manifested in the social activity of students and their teachers in a novel design and making environment? How do agency-structure dynamics create possibilities and obstacles for educational change? The data comprise 65 hours of video recordings and field notes of the social activity of students aged 9-12 years old ( $N=94)$ and their teachers collected over a period of one semester. Our study shows how the introduction of the novel learning environment created a boundary space in which traditional teacher-centered activity patterns interacted and came into tension with student-centered modes of teaching and learning. Our study reveals three distinctive agency-structure dynamics that illuminate how the agentive actions of both teachers and students stabilized existing teacher-centered practices and, at other, times ruptured and broke away from existing patterns, thus giving rise to possibilities for educational change.
\end{abstract}

\section{Keywords}

agency; structure; school; making and design environments; educational change 


\section{Introduction}

The education system in Finland has recently undergone national curriculum reform with the introduction of novel curriculum content, pedagogical approaches, and learning environments. The new core curriculum for the education of 7- to 16-year-olds emphasizes the development of students' critical thinking and learning-to-learn skills, interaction and expression, digital skills and multiliteracies, working life skills, and entrepreneurship as well as social participation and influence. The new curriculum also includes learning environments and pedagogies based on experiential, integrated, and student-centered learning; modeling real-life inquiry; and problem-solving with relevant social and material resources (Finnish National Board of Education, 2014, Pietarinen, Pyhältö, \& Soini, 2017).

The new Finnish core curriculum calls for major changes in the ways in which education has been organized in the past. The need for a more radical change is supported by earlier research that has indicated that Finnish teachers and their educational practices demonstrate traditional teachercentered and textbook-centered pedagogical approaches (Lahelma \& Gordon, 2003; Norris et al., 1996). Therefore, it is important to understand how the new curriculum is enacted and placed into use at the intersection of existing teaching and learning practices in Finnish schools and novel pedagogical approaches and learning environments being introduced. It is this transformation in the educational structures from teacher-centered instruction to more student-centered modes of teaching and learning that encapsulates our focus on educational change in this study.

Recognizing that educational change in schools is difficult (see also Osborne, Simon, Christodoulou, Howell-Richardson, \& Richardson, 2013; Ruthven et al., 2017), and understanding that agency is an important mediator of educational change (e.g., Rajala \& Kumpulainen, 2017), in our study, we investigate agency-structure dynamics in students and teachers' social activity in a Finnish school that has recently introduced a novel design and making environment as one means of addressing the new curriculum requirements. This design and making environment, the FUSE Studio, aims to support students' interest-driven engagement and learning in various kinds of science, crafts, robotics, and computing activities while creating material artefacts supported by a wide range of technologies and media in a social context. It also emphasizes relative expertise and students' agency in the learning activity (Stevens \& Jona, 2017).

In this study, we argue that, while novel learning and design environments are valuable and necessary for addressing the new curriculum requirements focusing on more student-centered modes, there is a need for a more nuanced understanding of how agency-structure dynamics create barriers and opportunities for such educational change efforts in everyday school life. Furthermore, we argue that, instead of examining student or teacher agency separately, it is important to understand their mutual interdependence and interplay in social activity. We hold that this knowledge is pivotal for understanding and supporting educational change in schools. The Finnish education system creates an intriguing research context for the study of agency-structure dynamics in relation to educational change, as this system provides teachers a great amount of autonomy to design and implement their teaching and to take evaluative control of students' learning progressions based on their professional knowledge and decision-making (EURYDICE, 2004; Sahlberg, 2011; Simola, 2015). It is in this sociocultural context that we ask the following questions: How are agency-structure dynamics manifested in the social activity of students and their teachers in a novel school-based design and making environment? How do agency-structure dynamics create possibilities and obstacles for educational change? 


\section{Conceptualizing and understanding agency-structure dynamics in formal education}

Our study draws on sociocultural and cultural-historical theorizing that defines agency as the capacity of people to act upon, influence, and transform their activities and circumstances (Engeström, 2006; Holland et al., 1998; Lipponen \& Kumpulainen, 2011; Rajala, 2016). This theoretical standpoint stresses the central role of mediation in human activity, that is, how agency is mediated by the purpose of the given activity and the availability and use of conceptual and practical tools (Wertsch et al., 1993). Agency is hence constituted in relation to other people in sociocultural contexts (Edwards, 2011; Holland et al., 1998). Taken together, agency is viewed as an ongoing complex, multi-faceted, historically situated process, and relational phenomenon, mediated through sociomaterial and cultural signs, tools, and contexts (Lipponen \& Kumpulainen, 2011; Rajala, 2016).

From the sociocultural and cultural-historical standpoint, agency and structure do not oppose but presuppose each other in a dialectical relationship; that is, structures shape people's agency, and conversely, people's agency reproduces and/or transforms structures (Emirbayer \& Mische, 1998; Giddens, 1984; Sewell, 1992). Agency results from the interplay of individual efforts, available resources, and contextual and structural elements (Biesta \& Tedder, 2007; Leander \& Osborne, 2008).

A number of previous studies on learning and education have investigated student and teacher agency in connection to the transformation of educational practice (e.g., Goulart \& Roth, 2010; Gutierrez \& Calabrese Barton, 2015; Rajala \& Kumpulainen, 2017; Siry \& Lang, 2010; Siry, Wilmes, \& Haus, 2016; Varelas, Martin, \& Kane, 2015). In the context of the school, opportunities for active participation and intentional membership in educational activities are found to be important in positioning students as actors and authors of their learning (Brown \& Renshaw, 2006; Greeno, 2006; Kumpulainen \& Lipponen, 2010). Previous research has also pointed out how student agency is a key to their relational engagement (Edwards, 2011). Even in most restricted settings characterized by accountability and control mechanisms, there is room for teachers and students to achieve some degree of agency (Buxton et al., 2015; Gresalfi et al., 2011; Robinson, 2012). For instance, Priestley et al. (2012) showed how teachers managed tensions between educational ideals and actual constraints of the work by taking risks and experimenting with the imposed constraints. Rajala \& Sannino (2015) showed how students agentively adapted the rigid demands of their assignments by cheating and secretly breaking the rules to get their work done. In contrast, Siry et al. (2016) showed how open-ended structures associated with participatory curricular design could create scope for new interactions and roles for both students and teachers. In sum, previous studies on agency have stated that achieving different degrees and forms of agency relates to issues such as the organization of school practices and the use of different pedagogical approaches (Gresalfi et al., 2009; Lipponen \& Kumpulainen, 2011; McFarlain, 2001).

\section{a. Stabilization knowledge and possibility knowledge as mediators of educational change}

In efforts to unpack agency-structure dynamics from the perspective of sociocultural and culturalhistorical theorizing, our study utilizes Engeström's (2007) conceptualization of stabilization knowledge and possibility knowledge by placing stabilized institutionalized structures of the school and novel emerging practices into constructive interplay with the participants' agentive actions. Given our focus on the historical development of stabilized practices mirrored against participants' agency in a novel learning environment, we hold that the notions of stabilization knowledge and possibility knowledge offer useful heuristics for the study of agency-structure dynamics in institutionalized educational contexts. 
Typically, in an institutional practice, such as a school, participants actively work to maintain stability as a way of creating coherence and dealing with the complex reality of their everyday practice (Engeström, 2007). While such stabilization efforts realized through the use of stabilization knowledge witness human agency to resist change, and to a certain extent, are necessary for the smooth functioning of an institution, they also constrain organizational learning and educational change. In particular, stabilization efforts often limit seeing and, most importantly, enacting alternative possibilities for educational change (Engeström, Engeström \& Suntio, 2002; Hennessy et al., 2015; Zellermayer, 2001).

Possibility efforts realized through the use of possibility knowledge, however, stand for participants' agentive actions toward breaking away from stabilized categorical knowledge and practices, which stresses the multivoicedness of interests and the future orientation of the activity (Engeström, 1996, 2007; Miettinen, 1999). Putting inert stabilization knowledge into movement and generating and enacting possibility knowledge in social activity is demanding and requires not just single mediating tools but multi-level instrumentality. In institutional settings, like schools, a qualitative transformation of an activity may be triggered by the introduction of new tools and technology, giving rise to agentive actions that draw upon possibility knowledge. However, transformation of practice is not reducible to new tools and/or technology only (Engeström, 2004). The generation of possibility knowledge especially calls for creative agentive actions and collaborative coconfiguration processes (Engeström, 2007).

In sum, in our study, we investigate the agentive actions of students and teachers at the intersection of established educational practice and a novel design and making environment. We view the novel learning environment as creating a boundary space in which stabilization knowledge and possibility knowledge meet, interact, and come into tension in the social activity of students and teachers, thus manifesting obstacles and opportunities for educational change.

\section{Study overview}

The empirical data of our research stems from a Finnish city-run comprehensive school with 535 students and 28 teachers at the primary level. Like any other school in Finland, this one follows the new national core curriculum, which has been defined locally. The local curriculum of the school strives for student-centeredness and stresses design learning, which is considered to enhance students' creative problem-solving skills across the curriculum (as expressed in its local curriculum document of 2016). ${ }^{1}$ As a response to the new curriculum requirements, the school has recently (in autumn 2016) introduced a new making and design environment called the FUSE Studio (www.fusestudio.net) as part of its elective courses.

\section{a. The FUSE Studio}

The FUSE Studio is a making and design environment, 'a choice-based digital infrastructure for STEAM (i.e., Science, Technology, Engineering, Arts, Mathematics) learning' (see Stevens \& Jona, 2017). The technological infrastructure of the FUSE environment offers students different STEAM challenges that 'level up' in difficulty like video games. The challenges include "Spaghetti Structures," "Jewelry Designer," "Robot Obstacle Course," "Keychain Customizer," Electric Apparel," "Coaster Boss," and "Solar Roller." The challenges are accompanied by various tools,

\footnotetext{
${ }^{1}$ The name of the school has been withheld for reasons of anonymity.
} 
such as computers, three-dimensional (3D) printers, and other materials (e.g., foam rubber, a marble, tape, and scissors), as well as instructions on how to process the challenges.

Each FUSE challenge is designed to engage students in different STEAM topics and skill sets. The challenges have been carefully structured to introduce students to new ideas and to support them through more complex iterations of those ideas. Students can choose, based on their own interests, which challenges they want to work on, when, and with whom. They can choose to work alone or with peers. There is no formal grading or assessment by teachers. Instead, using photos, video, or other digital artefacts, students can document their completion of a challenge, and the completion unlocks the next challenge in a sequence. Figure 1 below shows a student view of the FUSE challenges on a computer screen.

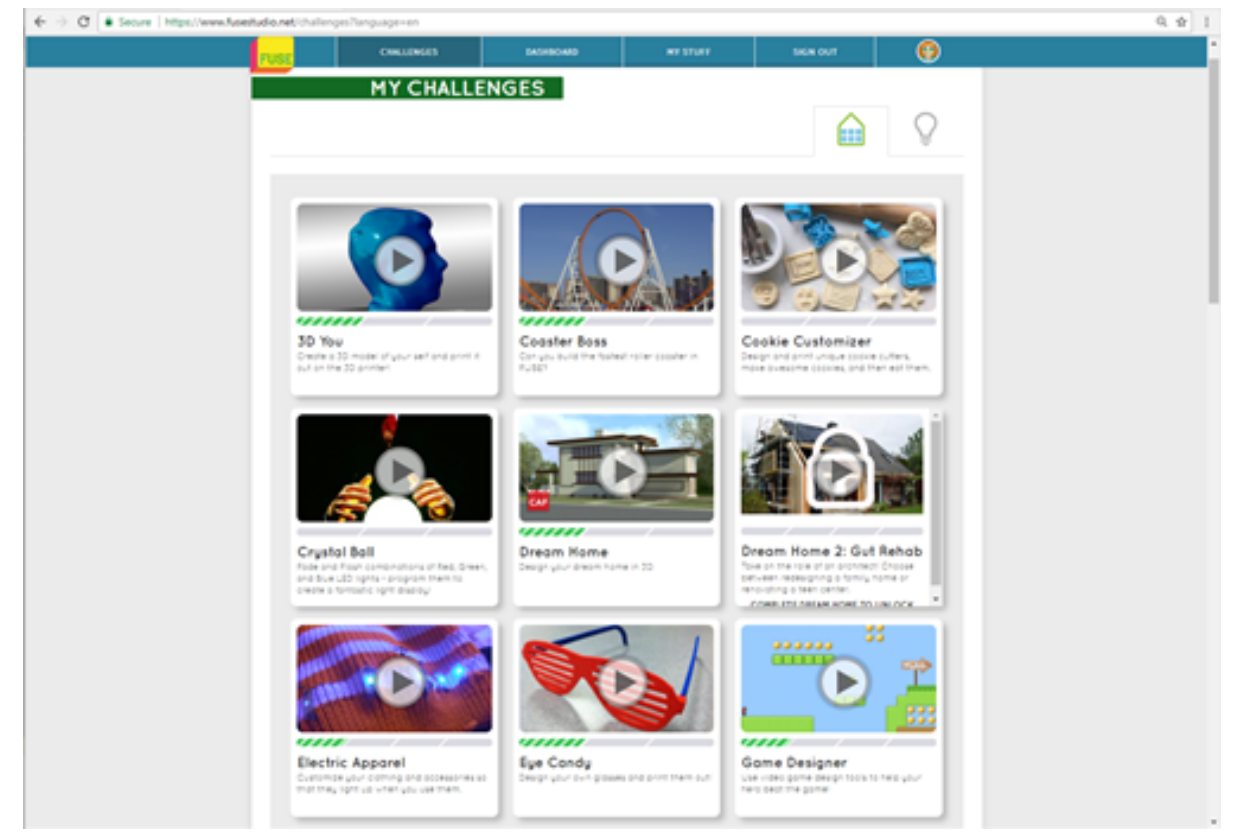

Figure. 1. "My Challenges" student interface

A combination of four elements in the FUSE Studio model creates a distinctive making and design environment: (1) an interest-driven approach, in which students are free to select which tasks ("challenges") to pursue and when to move on; (2) a levelling-up structure of challenges within sequences that follows the basic logic of video game design principles (e.g., Salen \& Zimmerman, 2005); (3) a focus on STEM ideas and practices, with a move toward STEAM, that includes artistic and design considerations in the criteria by which challenges are posed and judged; and (4) a core focus on cultivating interest in STEM ideas and practices among those who are not already affiliated with them, thereby aiming to broaden access to participation in STEM learning (see also Stevens \& Jona, 2017).

\section{Methods}

The primary data of this study comprise 65 hours of video recordings and field notes of students $(\mathrm{N}=94)$ between the ages of 9 and 12 years old and their teachers participating in making and design activities. The video recordings were collected intermittently over a period of one semester. The data come from three different groups of students and their teachers who participated in the 
FUSE Studio elective course. Due to the elective nature of the course, the groups were made up of students from several classes. Group 1 consisted of 32 students (22 boys and 10 girls), Group 2 consisted of 30 students ( 19 boys and 11 girls), and Group 3 consisted of 32 students (19 boys and 13 girls). Each group was supported by two to four teachers and teaching assistants. At the beginning of the autumn, each group had one 45-minute FUSE session per week. Later in the autumn, each session was extended to 60 minutes.

The video data and field notes of students and teachers' social activity in the design and making environment were transcribed and analyzed using interaction analysis methods (Jordan \& Henderson, 1995). Our analytic approach can be defined as abductive, involving repeated iterations between theory and data (Van Maanen et al., 2007). Our analysis of the agency-structure dynamics proceeded through three major phases. During the first phase, we inductively depicted stabilization knowledge from the students' and teachers' agentive actions that reflected traditional patterns of activities of school work, for instance, activities that were teacher-centered and/or guided by the learning materials. In this phase, we also depicted instances where the students' initiatives were overrun by the teachers.

In the second phase of our analysis, we identified possibility knowledge, by which we refer to the students' and teachers' agentive actions that gave evidence of breaking away from traditional enactments of doing school and that were more in line with the curriculum requirements emphasizing students' agency and interest in their learning activity. Possibility knowledge manifested itself in the student-initiated and/or teacher-initiated activities in which the students' interests were recognized and taken into account in reframing the activity. Possibility knowledge also manifested itself in social activity that deviated from the teachers' initial instructions or extended the original FUSE challenges, creating a space for the students' agency and recognition of their interests. In the third phase of the analysis, we investigated the interaction and tensions between stabilization knowledge and possibility knowledge in the students' and teachers' social activity with the aim of identifying how these interactions created obstacles and opportunities for educational change in the sociocultural context of the novel learning environment.

\section{Findings}

Our study reveals three distinctive agency-structure dynamics: maintaining existing patterns of activity; breaking away from existing patterns of activity; and collective uptake of new patterns of activity. These dynamics illuminate how the agentive actions of both the teachers and students stabilized the existing practices of the school and, at other times, ruptured and broke away from existing patterns of activity, giving rise to possibilities for educational change.

\section{a. Vignette 1: Maintaining existing patterns of activity}

In Vignette 1, a student, Iida, finds it difficult to upload her challenge onto the FUSE Studio website, and she asks the teacher for help. Another student, Laura, approaches the teacher at the same time in order to show her the gloves she has made in the "Electric Apparel" challenge. "Look what I did," Laura exclaims to the teacher, who is paying attention only to Iida's computer screen and advising her. The two students have to compete for their teacher's attention, and as the teacher is focusing on Iida, Laura leaves the situation. Iida and the teacher continue with the upload, and Laura comes back a little later to explain to the teacher her solution for loose threads in her gloves. The teacher turns her attention to Laura and comments, "Wow, unbelievable!" The teacher turns back to Iida and tells her what to do next. Then, she continues to listen to Laura's 
explanation and nods in agreement. After telling Iida to click "send," she turns back to Laura and tells her to take her unfinished gloves home so that they are safely stored until next week's lesson. Both students now know what to do, and the teacher leaves.

In this vignette, we witness the use of stabilization knowledge accompanying the students' agentive actions that is more typical of traditional classrooms. The students turn to the teacher (and not to each other) to ask for help and to share the outcomes of their work. In this vignette, the teacher maintains her traditional expert position and teacher-centered style of instruction and interaction with the students. We can also depict how the central role of the teacher in coordinating and mediating many simultaneous activities in the FUSE Studio creates a tension in the attempt to meet every students' needs. The teacher is unable to simultaneously guide and instruct the two students and, in addition, to oversee the whole FUSE class with its large number of students, each making choices about which challenges they prefer to work with and how. The students also strengthen this pattern of activity by turning to the teacher when they face an obstacle during their assignments and by demonstrating their progress and outcomes only to the teacher.

The way the students and teacher manage the tension contradicts the FUSE Studio's principles, also advocated by the new Finnish core curriculum, emphasizing relative expertise as well as collaborative peer learning and sharing. These principles embody possibility knowledge with a potential for destabilizing the existing knowledge practices. However, possibility knowledge, which encourages the reciprocal sharing and relative expertise that is advocated by the FUSE Studio (cf. Penney, 2016), was not activated in this case. Instead, the agency-structure dynamics enforced maintaining the traditional classroom practice in which the teacher is at the center, and the students missed opportunities to engage in a learning activity with collective responsibility and accountability for the learning activity and its material outcomes.

\section{b. Vignette 2: Breaking away from existing patterns of activity}

In Vignette 2, two students, Jesse and Jiri, are working on the "Spaghetti Structures" challenge. They are using several types of spaghetti and marshmallows to design and build big joint construction. The teacher comes to the students to let them know that there are only a few minutes left and that they should start cleaning up. The teacher reminds the students that they should take a picture of their achievement (a requirement of the FUSE Studio). Jesse asks whether they have to disassemble the construction, as he would rather not do so. The teacher instructs him to take a picture and then disassemble the construction. Another teacher joins them and asks if the students timed their work as they were supposed to do. Jesse informs the teacher that they "just forgot." The teacher asks the students about their aims for the challenge, implicitly evidencing her expectation of a goal-oriented activity. The students explain their construction to the teacher. The teacher continues to ask the students to specify what the challenge entailed, and they explain that the challenge was to get the big marshmallow to stay on top of the construction. The teacher replies, "Yes, but what were the instructions?" The students do not answer. Another teacher walks by and says, "If I remember correctly, the challenge was to use a certain amount of spaghetti and marshmallows and to do it in a certain time. There's a timer that you should have been using." The boys reply that they did not notice the instruction about the timer. The teacher tells them, "Go and clean up now. You're using up the whole group's spaghetti and marshmallows, and the others can't take on this challenge." The students clean up.

In this vignette, the students focused enthusiastically on their joint activity of designing a large construction using spaghetti and marshmallows. The activity was initiated by a FUSE challenge, but soon the students started to follow their own ideas and ways of working. The students found the "Spaghetti Structures" challenge so compelling that they ignored that the instructions imposed a time constraint for their construction challenge and instead strived to create something 
extraordinary. In sum, this case represents an example of where the students' agentive actions go beyond the instructions and the demands of the FUSE Studio and the teacher. We interpret this as a possibility act toward an expansive learning experience. Yet, at the same time, this vignette demonstrates tensions between the rules and instructions of the teacher and FUSE Studio and those made up by the students, with the students showing evidence of resistance to expected ways of working. Hence, in this example, we can witness the students destabilizing their existing knowledge and transitioning toward generating possibility knowledge in the creation of their own rules for their design and making activity. Yet, this breaking away from the expected patterns of activity is not accepted by the teachers, which results in an unresolved tension between the students' and teachers' interests and motives.

\section{c. Vignette 3: Collective uptake of new patterns of activity}

In Vignette 3, Kasper wants to start working on the "Jewelry Designer" (a FUSE Level 1 challenge). He asks the teacher for help. Leevi is standing behind Kasper and wants to know what Kasper is going to do. Kasper explains that he is going to design a wristband and print it out with the 3D printer when it arrives. The instructions for the challenge are in English, and the teacher translates the instructions for Kasper. These instructions ask the student to design a simple earring. Kasper does not want to design earrings and asks the teacher if he can design something else. The teacher replies that, in this level, he is supposed to design earrings so that he can begin to understand the role of product size in the design process. The teacher then wonders out loud if Kasper could, nevertheless, design something else the same size as an earring. Leevi suggests that Kasper could design a "finger thing," and the teacher agrees because a "finger thing" is about the same size. The teacher again highlights that the idea is to measure the design.

In this vignette, Kasper's motive to create a wristband and the demand built into the FUSE challenge (to create earrings) did not match and, thus, created a tension. The vignette demonstrates how a novel learning environment, such as the FUSE Studio with its aim of promoting interest-driven learning, can turn into a traditional classroom activity in which the student has to follow tasks and instructions with no opportunities for creative deviations from the plan. In this case, a productive resolution was reached, with the teacher and another student, Leevi, coming up with an alternative design idea that still met the learning goals set for the task. The fulfilment of Kasper's interest was reached through social interaction between the teacher and the other student, and the teacher, together with the student, created an alternative, yet equally productive, design and making activity that met the student's interest. Here, the teacher's interpretation of the learning goal of the challenge is instrumental, in the sense that the teacher interprets the task not as being specifically about designing an earring (i.e., carrying out a school task) but more broadly as being about designing a small item (i.e., acquiring expertise in the design process). This tension fostered the generation of possibility knowledge with the learning activity, leading to a resolution that Kasper found meaningful. The teacher and a student together enhanced the possibility of transforming the activity in the FUSE Studio by creating a space for this alternative but equally relevant process.

\section{Discussion}

In spite of emerging interest in the study of agency-structure dynamics in education, there is a paucity of knowledge of how these dynamics give rise to obstacles and possibilities for educational change. To contribute to bridging this research gap, we have applied sociocultural and culturalhistorical theorizing, with a specific interest in the heuristics of stabilization knowledge and 
possibility knowledge, to the research and understanding of the dialectic movement between students' and teachers' agentive actions situated at the intersection of the novel learning environment of the FUSE Studio and established school practices in the context of the Finnish school system, which has recently undergone a major curricular reform. We hold that, through examination of the agency-structure dynamics and tensions made visible in the social interactions between students and teachers, it is possible to shed light on the varied-and often contradictoryinstitutional and activity-related opportunities and constraints for educational change.

Our study shows how the introduction of the novel design and making environment of the FUSE Studio, which resonated with the new curriculum requirements, created a boundary space in which existing patterns of activity of doing school interacted and came into tension with new ways of teaching and learning. Our study reveals three distinctive agency-structure dynamics: maintaining existing patterns of activity; breaking away from existing patterns of activity; and collective uptake of new patterns of activity. These dynamics illuminate how the agentive actions of both teachers and students, analyzed from the perspective of stabilization knowledge and possibility knowledge, maintained the existing practices of the school and, at other times, ruptured and broke away from existing patterns of activity, thus giving rise to possibilities for educational change.

Agency-structure dynamics that provided evidence of maintaining existing patterns of activity illuminate how the students' agentive actions in the FUSE Studio drew on stabilization knowledge and were strongly embedded with their earlier schooling experiences, including following those rules and activity patterns. In this first vignette, the teacher enforced more teacher-centered ways of working and being at school by acting as the center of the students' activity. As a result, opportunities were missed for relative expertise as well as for collective responsibility and accountability of the learning activity and its material outcomes (Kumpulainen, Kajamaa, \& Rajala, forthcoming; Penney, 2016).

Agency-structure dynamics that broke away from existing patterns of activity demonstrate how the students' agentive actions in response to a FUSE challenge strengthened in the process of their work to the extent that they disregarded the original demands of the FUSE Studio and their teacher. This second vignette demonstrates the students' use of possibility knowledge in their agentive action, evidenced by their strong and persistent engagement in generating creative ideas and initiatives, especially when the content of a challenge was intriguing and meaningful to them. Here, the students created a social context for their collective creative activity and joint decisionmaking. Yet, this agentive initiation of the students demonstrating possibility knowledge came into tension with the teachers' actions and, hence, remained unresolved.

The agency-structure dynamics that evidence collective uptake of new patterns of activity demonstrate how a tension between the students' agentive actions and the structure of the FUSE Studio triggered a productive agency-structure dynamic drawing on possibility knowledge that took the students' learning activity beyond the given FUSE Studio challenge to meet the students' interests and engagement. In the third vignette, the teacher's interpretation of the FUSE challenge was instrumental in transforming the activity into a meaningful one for the students and in facilitating a space for joint problem-solving between himself and the students.

In sum, our study unfolds agency-structure dynamics in which both the students' and teachers' agentive actions enforced traditional teacher-centered and teacher-controlled schooling activity. The uptake of stabilization knowledge in the teachers and students' agentive activities are known to be especially demanding to deal with and difficult to overcome since they relate to the historically established rules of the school system (Engeström, 2007). At the same time, stabilization knowledge serves teachers and students in managing and dealing with the new learning environment and in making sense of educational reform in general. 
The tension-laden interplay between the students' and teachers' agency and the structures of their activities in the FUSE Studio can be seen, at the same time, as a driver for educational change. Tensions and discontinuities are often considered harmful, but they can be important opportunities for learning, both among the students and their teachers as well as across whole school communities (Hubbard, Mehan, \& Stein, 2006). As two of our vignettes show, tensions in the agency-structure dynamics generated by the teachers and students' use of possibility knowledge have the transformative power to develop the existing educational practice toward studentcentered learning. Particularly, Vignette 3 demonstrates how this is enabled if possibility knowledge is part of a shared agentive activity for both the teacher and students.

Our findings give evidence of the importance of technological infrastructures and digital artefacts, in other words "instrumentalities", as essential mediating devices for putting inert stabilization knowledge into movement and creating opportunities for the use of possibility knowledge. However, transformation of practice is often difficult and not reducible to new tools and/or technology (Engeström, 2004). Generating and enacting possibility knowledge in social activity is a particularly demanding process and requires versatile mediating tools, creative actions and collaborative co-configuration processes (Engeström, 2007). In such cases, the traditional (stabilized) and the novel (possibility) tools, materials and procedures successfully came together, creating a "multi-level instrumentality" of learning where the aims and expectations of the new curriculum and the collective STEAM learning processes are productively intertwined.

Our study's main message for teachers in the context of educational change is that they need to increasingly exercise their professional agency and reflective thinking to find a balance between old and new ways of working (Kramer, 2018; Rajala \& Kumpulainen, 2017). In sum, navigating agency-structure dynamics in the context of educational reform requires constant effort, both from teachers and students. Bridging the gap between established school practices and students' making and design activities can thus be viewed as a continuous process of collective learning. As suggested by earlier research, the emergence of new ways of working and of being at school requires instrumental genesis and calls for co-evolution of schools' social and technological infrastructures (Hakkarainen, 2009; Kumpulainen, Mikkola, \& Jaatinen, 2014).

\section{Conclusions}

In summary, our study shows how both teacher and student agency, accompanied by possibility knowledge, are required to make space for transforming practice and educational change. By understanding such conditions and opportunities for relative agency (Edwards, 2011) between teachers and students, we can begin to help schools and other educational institutions more systematically and consciously implement educational change.

As our study shows, researching agency-structure dynamics informed by sociocultural and culturalhistorical theorizing has much to offer toward understanding the potential of new learning environments and arrangements for educational change. Investigation into agency-structure dynamics from the perspective of stabilization knowledge and possibility knowledge helps us understand the conditions under which the educational change potential of novel learning environments can be realized or thwarted. Furthermore, our study is a beginning for more longitudinal studies of agency-structure dynamics in students and teachers' social activity for sustained educational change. 


\section{Acknowledgments}

We would like to thank Ms. Jasmiina Korhonen and Riikka Olkinuora for their help in data collection and analysis. We would also like express our sincere gratitude and thanks to all students and teachers who participated in our study. This research reported in this study has been financially supported by the Academy of Finland (no: 1310790).

\section{References}

Biesta, G., \& Tedder, M. (2007). Agency and learning in the lifecourse: Towards an ecological perspective. Studies in the Education of Adults, 39(2), 132-149.

Brown, R., \& Renshaw, P. (2006). Positioning students as actors and authors: a chronotopic analysis of collaborative learning activities. Mind, Culture, and Activity, 13(3), 247-259.

Buxton, C. A., Allexsaht-Snider, M., Kayumova, S., Aghasaleh, R., Choi, Y., \& Cohen, A. (2015). Teacher agency and professional learning: Rethinking fidelity of implementation as multiplicities of enactment. Journal of Research in Science Teaching, 52(4), 489-502.

Edwards, A. (2011). Building common knowledge at the boundaries between professional practices: Relational agency and relational expertise in systems of distributed expertise. International Journal of Educational Research, 50(1), 33-39.

Emirbayer, M., \& Mische, A. (1998). What is agency? American Journal of Sociology, 103(4), 962-1023.

Engeström, Y. (1996). Development as Breaking Away and Opening Up: A Challenge to Vygotsky and Piaget. Swiss Journal of Psychology, 55, 126-132.

Engeström, Y. (2004). The new generation of expertise: Seven thesis. In H. Rainbird, A Fuller \& A. Munro (Eds.), Workplace learning in context (pp. 145-166). London: Routledge.

Engeström, Y. (2006). Development, movement and agency: Breaking away into mycorrhizae activities. In K. Yamazumi (Ed.), Building Activity Theory in Practice: Toward the Next Generation (pp. 1-43). Kansai: Kansai University Press.

Engeström, Y. (2007). From Stabilization Knowledge to Possibility Knowledge in Organizational Learning. Management Learning, 38(3), 271-275

Engeström, Y., Engeström, R. \& Suntio, A. (2002). Can a School Community Learn to Master its Own Future? An Activity-Theoretical Study of Expansive Learning Among Middle School Teachers. In G. Wells and G. Claxton (Eds.), Learning for Life in the 21st Century: Sociocultural Perspectives on the Future of Education (pp. 211-224). Blackwell Publishing Ltd, Oxford, UK.

EURYDICE. (2004). Evaluation of schools providing compulsory education in Europe. European Commission. Directorate-General for Education and Culture. Brussels: Eurydice, European Unit.

Giddens, A. (1984). The constitution of society: Outline of the theory of structuration . Cambridge: Polity Press.

Goulart, M. I. M., \& Roth, W. M. (2010). Engaging young children in collective curriculum design. Cultural Studies of Science Education, 5(3), 533-562.

Greeno, J. (2006). Authoritative, accountable positioning and connected, general knowing: Progressive themes in understanding transfer. The Journal of the Learning Sciences, 15, 537-547.

Gresalfi, M., Martin, T., Hand, V., \& Greeno, J. (2009). Constructing competence: An analysis of student participation in the activity systems of mathematics classrooms. Educational Studies in Mathematics, 70(1), 49-70.

Grossen, M., Zittoun, T., \& Ros, J. (2012). Boundary crossing events and potential appropriation space in philosophy, literature, and general knowledge. In E. Hjörne, G. van der Aalsvoort, \& G. de Abreu (Eds.), Learning, social interaction, and diversity-exploring identities in school practices (pp. 15-33). Rotterdam: Sense Publishers. 
Gutiérrez, K. D., \& Calabrese Barton, A. (2015). The possibilities and limits of the structure-agency dialectic in advancing science for all. Journal of Research in Science Teaching, 52(4), 574-583.

Hakkarainen, K. (2009). A knowledge-practice perspective on technology-mediated learning. International Journal of Computer-Supported Collaborative Learning, 4, 213-231.

Hennessy, S., Haßler, B., \& Hofmann, R. (2015). Challenges and opportunities for teacher professional development in interactive use of technology in African schools. Technology, Pedagogy and Education, 24(5), 1-28.

Holland, D., Lachiocotte, W., Skinner, D., \& Cain, C. (1998). Identity and agency in cultural worlds. Cambridge, MA: Harvard University Press.

Hubbard, L., Mehan, H., \& Stein, M.K. (2006). Reform as learning: When school reform collided with school culture and community politics in San Diego. New York: Routledge.

Jordan, B. \& Henderson, A. (1995). Interaction analysis: Foundations and practice. Journal of the Learning Sciences, 4(1), 39-103.

Leander, K., \& Osborne, M. (2008). Complex positioning: Teachers as agents of curricular and pedagogical reform. Journal of Curriculum Studies, 40(1), 23-46.

Kramer, M. (2018). Promoting teachers' agency: reflective practice as transformative disposition. Reflective Practice, DOI: 10.1080/14623943.2018.1437405

Kumpulainen, K. (2017). Makerspaces: Why they are important for digital literacy education. In J. Marsh, et al., (Eds.), Makerspaces in the Early Years: A Literature Review (pp. 12-16). University of Sheffield: Makey Project. Retrieved from http://makeyproject.eu/wpcontent/uploads/2017/02/Makey Literature Review.pdf

Kumpulainen, K., \& Lipponen, L. (2010). Productive interaction as agentic par- ticipation in dialogic enquiry. In K. Littleton \& C. Howe (Eds.), Educational Dialogues. Understanding and Promoting Productive Interaction (pp. 48-63). London: Routledge.

Kumpulainen, K., Mikkola, A., \& Jaatinen, A. M. (2014). The chronotopes of technology-mediated creative learning practices in an elementary school community. Learning, Media and Technology, 39(1), 53-74.

Lasky, S. (2005). A sociocultural approach to understanding teacher identity, agency and professional vulnerability in a context of secondary school reform. Teaching and teacher education, 21(8), 899916.

Lipponen, L., \& Kumpulainen, K. (2011). Acting as accountable authors: Creating interactional spaces for agency work in teacher education. Teaching and Teacher Education, 27(5), 812-819.

McFarland, D. (2001). Student resistance: How the formal and informal organi- zation of classrooms facilitate everyday forms of student defiance. American Journal of Sociology, 107(3), 612-678.

Miettinen, R. (1999). The Riddle of Things: Activity Theory and Actor-Network Theory as Approaches to Studying Innovations. Mind, Culture and Activity, 6(3), 170-195.

Finnish National Board of Education (2014). Perusopetuksen opetussuunnitelman perusteet 2014 [National Core Curriculum for Basic Education 2014] Accessed from http://www.oph.fi/download/163777 perusopetuksen opetussuunnitelman perusteet 2014.pdf

Penney, L. R. (2016). An investigation into how students select and develop resources for learning as they pursue choice-based STEAM challenges. Doctoral dissertation. Northwestern University.

Pietarinen, J., Pyhältö, K. \& Soini, T. (2017) Large-scale curriculum reform in Finland - exploring the interrelation between implementation strategy, the function of the reform, and curriculum coherence. The Curriculum Journal, 28(1), 22-40.

Priestley, M., Edwards, R., Priestley, A., \& Miller, K. (2012). Teacher agency in curriculum making: Agents of change and spaces for manoeuvre. Curriculum Inquiry, 42(2), 191-214.

Rainio, A. P., \& Hilppö, J. (2017). The dialectics of agency in educational ethnography. Ethnography and Education, 12(1), 78-94.

Rajala, A. (2016). Toward an agency-centered pedagogy - A teacher's journey of expanding the context of school learning. PhD Dissertation. University of Helsinki: Department of Teacher Education. 
Rajala, A., \& Kumpulainen, K. (2017). Researching teachers' agentic orientations to educational change in Finnish schools. In M. Coller \& S. Paloniemi (Eds.), Agency at Work: An Agentic Perspective on Professional Learning and Development (pp. 311-329). Amsterdam: Springer.

Rajala, A. \& Sannino, A. (2015). Students' deviations from a learning task: An activity-theoretical analysis. International Journal of Educational Research, 70, 31-46.

Robinson, S. (2012). Constructing teacher agency in response to the constraints of education policy: adoption and adaptation. Curriculum Journal, 23(2), 231-245.

Sahlberg, P. (2011). The fourth way of Finland. Journal of Educational Change 12(2), 173-185.

Salen, K., \& Zimmerman, E. (2005). Game design and meaningful play. In J. Raessens \& J. Goldstein (Eds.), Handbook of computer game studies (pp. 59-79). Cambridge, MA: MIT Press.

Sewell, W. (1992). A theory of structure: Duality, agency and transformation. American Journal of Sociology, 98(1), 1-30.

Simola, H. (2015). The Finnish education mystery: Historical and sociological essays on schooling in Finland. New York, NY: Routledge.

Siry, C., \& Lang, D. (2010). Creating participatory discourse for teaching and research in early childhood science. Journal of Science Teacher Education, 21(2), 149-160.

Siry, C., Wilmes, S. E., \& Haus, J. M. (2016). Examining children's agency within participatory structures in primary science investigations. Learning, Culture and Social Interaction, 10, 4-16.

Stevens, R. \& Jona, K. (2017). Program Design. FUSE Studio website. Retrieved May 20, 2017 from https://www.fusestudio.net/program-design

Stevens, R., Jona, K., Penney, L., Champion, D., Ramey, K., Hilppö, J., ... Penuel, W. (2016). FUSE: An alternative infrastructure for empowering learners in schools. In C-K. Looi, J. Polman, U. Cress, \& P. Reimann (Eds.) Transforming Learning, Empowering Learners: 12th International Conference of the Learning Sciences (pp. 1025-1032). Retrieved from: https://www.isls.org/icls/2016/docs/ICLS2016_Volume_2.pdf

Van Maanen, J., Sørensen, J. B. \& Terence, R. M. (2007). The interplay between theory and method. Academy of Management Review, 32(4), 1145-1154.

Varelas, M., Settlage, J., \& Mensah, F. M. (2015). Explorations of the structure-agency dialectic as a tool for framing equity in science education. Journal of Research in Science Teaching, 52(4), 439-447.

Zellermayer, M. (2001) Resistance as a catalyst in teachers' professional development, in Clark, M. C. (Eds.) Talking Shop. Authentic Conversation and Teacher Learning (pp. 40-63). New York: Teachers College Press. 